УДК 811.112.2’276.6

DOI https://doi.org/10.26661/2414-9594-2021-1-14

\title{
ОСОБЛИВОСТІ УТВОРЕННЯ СКОРОЧЕНЬ У НІМЕЦЬКІЙ ФАХОВІЙ МОВІ ВИКЛАДАЧА
}

\author{
Кременсва Т. В. \\ аспірантка, \\ асистентка кафедри германської філологї \\ Дніпровський національний університет імені Олеся Гончара \\ вул. Гагаріна, 72, Дніпро, Украӥна \\ orcid.org/0000-0002-1933-900X \\ taniakremeneva@gmail.com
}

Ключові слова: абревіачія, фахова мова педагога німецької мови, ініціальні скорочення, комбіновані скорочення, усічені скорочення, акроніми.
У статті було проведене дослідження абревіації фахової німецької мови педагога як основного засобу мовної економії. У зв'язку із цим було проаналізовано поняття «абревіація» на основі численних праць українських та закордонних учених із цього питання. Абревіацію можна розуміти як скорочення з метою мовної економії під час спілкування спеціалістами однієї галуззі діяльності 3 ознаками вторинності, продуктивності, економії та самостійності. Було розглянуто основні способи систематизації скорочень 3 подальшим виокремленням їхньої єдиної структурної класифікації. До основних видів абревіатур належать ініціальні скорочення, комбіновані скорочення й усічені абревіатури. Ініціальні скорочення поділяються на акроніми, літерно-цифрові, літерні зі сполучником та парні літерні скорочення. До комбінованих належать літерно-словесні, усічені словесні та літерно-словесні скорочення із цифрами. Найбільшу кількість видів становлять усічені абревіатури, які можуть бути усіченими літерними, усіченням одного слова, усіченням та поєднанням частин декількох слів, усіченням та поєднанням першої та останньої літер слова, усіченням та поєднанням складів слова, усіченням та поєднанням літер, складів та частин слова, усіченням слова iз цифрами, усіченням слова 3 літерами та цифрами та телескопізмами (поєднання початкової та кінцевої частин слів). Відповідно до наведеної класифікації було проаналізовано основні види та кількість термінівабревіатур фахової німецької мови викладача 3 наведенням прикладів iз фахових журналів педагога німецької мови. Надалі було виокремлено 123 абревіатурні одиниці із загальної кількості 3000 термінів професійної мови викладача, що становить 4,1\% від їх загальної кількості. На основі проведеного дослідження було встановлено, що найбільшу кількість становлять акроніми та літерно-словесні скорочення. Помітна тенденція до збільшення кількості літерно-словесних скорочень, утворених у німецькій фаховій мові педагога на основі акронімів. Попри непродуктивність абревіатурних термінів, цей факт вказує на збільшення їхнього обсягу в німецькій фаховій мові викладача, що робить актуальним їх подальше дослідження. 


\title{
FEATURES OF FORMATION OF ABBREVIATIONS IN THE PROFESSIONAL LANGUAGE OF THE GERMAN TEACHER
}

\author{
Kremenieva T. V. \\ Postgraduate Student, \\ Assistant at the Department for Germanic Philology \\ Oles Honchar Dnipro National University \\ Gagarin str., 72, Dnipro, Ukraine \\ orcid.org/0000-0002-1933-900X \\ taniakremeneva@gmail.com
}

Key words: abbreviation, professional language of German teacher, initial abbreviations, contractions, shortenings, acronyms.
The article examines the abbreviation of the professional German language of the teacher as the main means of language economy. In this regard, the term "abbreviation" was analyzed on the basis of numerous works of Ukrainian and foreign scientists on this issue. The abbreviation can be understood as shortening for the purpose of language economy during communication between specialists in one professional area with features of secondary role, productivity, economy and independence. The main ways of systematization of abbreviations with the subsequent allocation of their uniform structural classification were considered. The main types of abbreviations are initial abbreviations, contractions and shortenings. The initial abbreviations, in turn, are divided into acronyms, alphanumeric abbreviations, letter abbreviations with conjunctions and doubleletter abbreviations. Contractions include letter-verbal abbreviations, verbal contraction and letter-verbal abbreviations with numbers. The largest number of abbreviation types are shortenings which can be letter shortenings, one-word shortenings, word-combination shortenings, letter-combination shortenings, syllable-combination shortenings, letter-syllable-word-combination shortenings, word shortenings with numbers, word shortenings with letters and numbers and telescopisms (combination of initial and final word parts). According to this classification, the main types and number of abbreviations of the professional language of the German teacher were analyzed with examples from the professional journals of the teacher of the German language. Subsequently, 123 abbreviation terms were distinguished from the total number of 3000 terms of the professional language of the teacher, which is $4,1 \%$ of the total number of the terms. Based on this research, it was found that the largest number are acronyms and letter-verbal abbreviations. There is a marked tendency towards an increase in the number of letter-verbal abbreviations, which are formed on the basis of acronyms in the German professional language of the teacher. In spite of the abbreviations as a non-productive way of term formation, this fact indicates an increase in their number in the German professional teacher language, which makes relevant their further research.
Постановка проблеми. Натепер із розвитком інформаційних технологій збільшуються потоки інформації, що призводить до появи нових термінів у різних фахових спеціальностях. Від фахівця вимагається їх досконале опанування та доречність використання у власній спеціальності. Занадто велика кількість нових термінів призвела до потреби мовленнєвої економії, що й стало причиною появи такого явища, як «скорочення», або «абревіація». Німецька професійна мова викладача не стала винятком, оскільки галузь освіти перебуває в постійному розвитку через виник- нення за останні десятиліття нових підходів та методів навчання іноземної мови із залученням новітніх електронних інформаційних ресурсів.

Аналіз останніх досліджень та публікацій. Поняття «абревіація» як засіб «скорочення структури» терміна зі «збереженням» його інформативного наповнення [4, с. 167] є об'єктом вивчення таких вітчизняних та закордонних учених: О. Петренко, В. Лейчика, 3. Потіхи, Н. Книшенко, О. Бірюкової, М. Дужи-Задорожньої, С. Кострубіної, К. Дюжикової, Л. Халіновської та інших. Проте й досі не було приділено 
уваги особливостям скорочень у німецькій фаховій мові педагога.

Мета статті полягає у визначенні частотності вживання абревіації в термінології професійної німецької мови викладача зі встановленням основних видів класифікації скорочень за їхніми структурними характеристиками. Завданнями $\epsilon$ дефініція поняття «абревіація», вивчення та виокремлення основних видів скорочень залежно від їхньої побудови, встановлення характерних особливостей абревіатур у фаховій мові педагога німецької мови. Для аналізу було відібрано терміни-скорочення із 3000 термінів німецької фахової мови викладача.

Виклад основного матеріалу дослідження. 3 теоретичного погляду поняття абревіації залишається актуальним для дослідження через неможливість надання йому вченими єдиного визначення та єдиної класифікації. У німецькомовних словниках абревіація розглядається як «рядок літер, що означає слово у скороченні» [24, с. 14], «скорочений порядок слів» [12, с. 83], «усічена форма слова» [26, с. 94]. На думку дослідниці Н. Книшенко, абревіатурами є скорочені терміни, які можна розглядати як одну 3 «ознак фахового мовлення», оскільки вони зрозумілі під час спілкування спеціалістами окремої галуззі діяльності [5, с. 21]. Скорочення виступає способом формування номінацій із деяких слів та словосполучень, тому абревіація $\epsilon$ «згортанням слів та словосполучень» зі збереженням їхнього первинного значення [3, с. 43]. Учені називають абревіатури «стягуванням словосполучень» 6 , с. 40] та «складанням слів» [1, с. 17] у скороченому вигляді. 3 наведених визначень можна зробити висновок, що абревіація $є$ скороченням слова або словосполучення для мовної економії під час спілкування між спеціалістами визначеного виду діяльності. Основними ознаками абревіатур є вторинність, тобто утворення від первинних слів або словосполучень, продуктивність, оскільки вони збагачують фахову мову спеціаліста новими термінами, економність - у разі скорочення занадто довгих словосполучень для уникнення їх повторної фіксації у фахових текстах, самостійність, тобто їх сприйняття як повноцінних окремих термінів у професійному спілкуванні.

Актуальною проблемою в дослідженні абревіатур $€$ виокремлення їх структурних типів, оскільки натепер ученими не надано єдиної структурної класифікації. Дослідниця М. Дужа-Задорожна виділяє акроніми як усічену форму, яка складається 3 «початкових літер» у «багатокомпонентній назві»; скорочення-контамінації як процес складання «двох основ» $\mathrm{i}$ абревіатури-анкопи як результат усічення, або «опускання частини слова» [2, с. 95]. Більш роз- ширену версію структурної класифікації надає Л. Халіновська, яка виділяє ініціальні абревіатури зі складанням перших літер (літерні абревіатури) слова або літер та цифр (цифрові абревіатури); комбіновані абревіатури зі складанням «твірного слова 3 літерами або цифрами» та графічні 3 «вичленовуванням першої літери» [7, с. 51]. Н. Книшенко пропонує класифікувати структурні абревіатури з їх подальшим розподіленням на «буквенні, звукові, буквенно-звукові та буквенно-цифрові», частково скороченні, сполучення початкових частин слів та комбіновані $[5$, с. 20]. У дослідженнях О. Бірюкової скорочення такі: ініціальні, складові, з утворенням слова 3 «початкових складів», змішані - у вигляді сполучення «літери зі словом», частково скорочені - у разі поєднання «частини слова із цілим словом», телескопічні - на основі злиття «початку та кінця слів», транскрипційні - у разі складання «компонентів початкових літер слова» [1, c. 24].

Як результат проведеного дослідження можна представити такі види абревіатур фахової мови викладача німецької мови:

1. Ініціальні абревіатури, які можна розподілити на літерні абревіатури-акроніми, які складаються 3 однієї літери (I - Inhalt, $\boldsymbol{R}$ - Rechtschreibfehler, $\boldsymbol{H}$ - Hypothalamus): "Bewertet werden, gemäß kultusministeriellem Beschluss, die sprachliche und die inhaltliche Leistung, $S$ (aus $A V$ u. SR) und I' [23, с. 373]; із двох літер (FU - Fremdsprachunterricht, $\quad$ LG Langzeitgedächtnis): "Für den FU heißt dies, dass als Basis für alle weiteren Überlegungen zunächst das Ziel der Ausbildung gilt" [11, с. 79]; із трьох літер (AVM - audiovisuelle Methode, MPS - Motorisches Programmsystem, KDS - Kleine deutsche Sprachdiplom): "Dazu zählen die zentrale Mittel- und Oberstufenprüfung und das Kleine und Große Deutsche Sprachdiplom (KDS/GDS)", [21, с. 385]; із чотирьох літер (ZDfB - Deutsch für den Beruf, $\boldsymbol{Z} \boldsymbol{f} \boldsymbol{s} \boldsymbol{L}$ - Die Zentren für schulpraktische Lehrerausbildung, $\boldsymbol{B I B B}$ - Bundesinstitut für Berufsbildung): "Der $\boldsymbol{B I B B}$ differenziert weder nach Schulformen noch nach Fächerwahl, sondern es setzt spektakuläre Zahl in die Landschaft" [18, c. 8]; з п'яти літер (GPRLL - Gesamtpersonalrat der Lehrerinnen und Lehrer): "Weiter wird damit (endlich) bestätigt, was der GPRLL auch bereits schon letzte Woche als Begründung für das Aussetzen von Dienstversammlungen und Konferenzen angeführt hatte: Aufenthalt in der Schule nur in Notfällen "[8, c. 2]; літерно-цифрові абревіатури $(\boldsymbol{G 8}$ - achtjähriger gymnasialer Bildungsgang, $\mathbf{G 9}$ - neunjähriger gymnasialer Bildungsgang, L1, L2 - Lesekompetenz): "Es geht nicht mehr allein um die Fähigkeiten in der Fremdsprache (L2), sondern vermehrt um 
sachfachliche Kompetenzen oder, wie im Fall der vorliegenden Studie, um Grundfertigkeiten, wie sie in den nationalen Bildungsstandards beschrieben sind" [22, с. 16]; парні літерні, які можуть складатися окремо за допомогою сполучників (HRSGe und $\boldsymbol{G}$ - Hauptschule, Realschule, Gesamtschule und Grundschule): "Diese mangelnde Wertschätzung und Ungerechtigkeit verärgert und belastet uns als Fachleiterinnen und Fachleiter im Lehramt HRSGe und $\boldsymbol{G}$ ” $[19$, с. 13], за допомогою сполучників в одну скорочену форму (SoS - Schülerin oder Schüler, $\boldsymbol{S u S - S c h u ̈ l e r i n n e n ~ u n d ~ S c h u ̈ l e r ) : ~ " F e s t ~ s t e h t , ~}$ dass die bilingual unterrichteten $\mathbf{S u S}$ oft motivierter sind als ihre Altersgenossen, denn die Entscheidung für bilingualen Unterricht hat eine leichte Erhöhung der Wochenstundenzahl zur Folge" [22, c. 13].

2. Комбіновані абревіатури, до яких можна віднести літери із цілими словами (DAZ-Didaktik, DAAD-Projekt): "Diese kognitiven Fähigkeiten sind in der DAZ-Didaktik im Hinblick auf den Vergleich zwischen der Erst- und Zweitsprache bedeutend" [9, с. 2], літери та цифри із цілими словами (G8-Abitur - achtjähriges Gymnasium): "Das G8-Abitur am Gymnasium entwickelt sich allmählich zu einem großen Stärkungsprogramm für Gesamtschulen und Sekundarschulen" [18, c. 20], усіченої форми слова із цілим словом (MigrosKlubschulen, Migros - Genossenschaftsbund): "Aus der Sprachschule wurden die MigrosKlubschulen. Sie sind etwa fünfmal größer als die Volkshochschulen" [25, c. 91].

3. Усічені абревіатури на основі поєднання початкових частин слів (F्̈ $\boldsymbol{R} \boldsymbol{M I G}-$ Förderung von Kindern und Jugendlichen mit Migrationsgrund): "Die Qualitätsmerkmale Durchgängiger Sprachbildung sind der Ertrag einer Arbeitsgruppe des Modellprogramms FörMig (Förderung von Kindern und Jugendlichen mit Migrationshintergrund)" [15, с. 7], усіченої початкової форми одного слова (Abi - Abitur, Prof. Professor), усіченої форми слова в разі поєднання першої й останньої літер (Dr. - Doktor): "Prof. Dr. Jochen Krautz und Dr. Matthias Burchardt, haben sich bereit erklärt, bei Veranstaltungen als Referenten und Diskutanten zur Verfügung zu stehen" [17, с. 11], поєднання декількох складів цілого слова (Azubi - Auszubildende): “Warum sollten Auszubildende nicht mit Schülerinnen und Schülern über ihren Weg in die Ausbildung und über ihr Leben als Azubi sprechen?" [13, с. 2], сполучення початкової частини слова, складу слова та літер (SprasiBEQ - Sprachsensibilierung in den beruflichen Qualifizierung): "In einem Projekt von SprasiBeQ haben Birnbaum, Kupke und Schramm ausgehend von einer Bedarfsanalyse und Unterrichtsbeobachtungen in einem differenziert ausgearbeiteten Forschungsdesign Kann-
Beschreibungen und Kompetenzbeschreibungen für Lehrkräfte <...> " [10, с. 73], поєднання усіченої початкової частини слова 3 літерами $(\boldsymbol{M}-\boldsymbol{S P R A}-$ Metasprache, BVerfG - Bundesverfassungsgericht): "das im Landauer Projekt entwickelte Verfahren M-SPRA unterscheidet sich maßgeblich von anderen, durchaus üblichen Verfahren" [27, c. 45], із цифрами (Sek-I-Sekundarschule II): "Lehrkräfte im Sek-I Bereich benötigen mehr Hilfe bei der Inklusion, Integration und bei der Digitalisierung" $[20$, c. 22], літер із цифрами (G9-Abi neunjähriges Gymnasium): "Dort will die rot-grüne Landesregierung zum Schuljahr 2015/2016 zum guten alten G9-Abi zurückkehren" [18, с. 20]. Сюди також можна віднести телескопічні абревіатури в разі поєднання першої й останньої частин слів (MINTegration - minderheitliche Integration): "In dem Projekt MINTegration beschäftigen sich Lehramtsstudierende des Faches Biologie theoretisch und praktisch mit den Aspekten sprachsensiblen Unterrichts im Fach Biologie" [16, c. 2].

За походженням можна виокремити питомі німецькі абревіатури ( $\boldsymbol{Z} \boldsymbol{f} \boldsymbol{s} \boldsymbol{L}$ - Die Zentren für schulpraktische Lehrerausbildung): "Ein Prüfungstag Langzeitbeurteilung über achtzehn Monate durch Schule und $\boldsymbol{Z} f \boldsymbol{s} \boldsymbol{L}$ " [18, с. 6], запозичені з англійської мови абревіатури (FCE - First Certificate in English): "Die größte Nachfrage besteht nach dem Preliminary English Test (PET) und dem etwas höher angesiedelten First Certificate in English $(\boldsymbol{F C E})$ )" [21, с. 385], сполучення німецьких і англійських слів (VOLL-Ansatz - vocationally oriented language learning): "Dem deutschen Begriff berufsbezogener Fremdsprachenunterricht entspricht am ehesten der VOLL-Ansatz des Europarats" [14, c. 175].

Висновки і перспективи подальших досліджень. Проведений аналіз абревіатур фахової мови педагога німецької мови дозволив встановити таке співвідношення розгляду даних термінів за структурним способом утворення.

На основі наведених таблиць можна зробити висновок, що абревіація не є продуктивним засобом термінотворення фахової мови педагога німецької мови, оскільки становить лише $4,1 \%$ від загальної кількості термінів. Проте вона $є$ ефективним засобом мовної економії та компактності завдяки можливості скорочення занадто довгих слів. За структурною класифікацією найчастіше трапляються акроніми та літерно-словесні скорочення, де часто акроніми є джерелом утворення останніх (DAF - DAF-Lehrende, DAF-Unterricht, DAF-Didaktik). Це вказує на можливість утворення нових абревіатур, а значить, і збільшення їхнього обсягу в майбутньому. Тому ця тема заслуговує на подальше дослідження зі створенням спеціального глосарія скорочень із фахової мови викладача німецької мови. 
Таблиця 1

Структурний спосіб утворення абревіатур німецької фахової мови педагога

\begin{tabular}{|c|c|c|c|c|}
\hline № & Вид абревіатури & Приклад & Кількість & \% усіх термінів \\
\hline \multirow{5}{*}{1.} & \multicolumn{2}{|c|}{ Ініціальні скорочення } & 80 & 2,6 \\
\hline & Акроніми & FU (Fremdsprachenunterricht) & 73 & \\
\hline & Літерно-цифрові & $\begin{array}{c}\text { G8 (achtjähriger gymnasialer } \\
\text { Bildungsgang) }\end{array}$ & 4 & \\
\hline & Літерні зі сполучником & SoS (Schülerin oder Schüler) & 2 & \\
\hline & Парні літерні & $\begin{array}{l}\text { HRSGe und G (Hauptschule, Realschule, } \\
\text { Gesamtschule und Grundschule) }\end{array}$ & 1 & \\
\hline 2. & \multicolumn{2}{|c|}{ Комбіновані скорочення } & 28 & 1 \\
\hline & Літерно-словесні & DAZ-Didaktik (deutsch als zweite Sprache) & 22 & \\
\hline & Усічені словесні & Migros-Klubschulen & 4 & \\
\hline & Літерно-словесні із цифрами & G8-Abitur (achtjähriges Gymnasium) & 2 & \\
\hline 3. & \multicolumn{2}{|c|}{ Усічені абревіатури } & 15 & 0,5 \\
\hline & Усічені літерні & SchulG (Schulgesetz) & 4 & \\
\hline & Усічення одного слова & Abi (Abitur) & 4 & \\
\hline & $\begin{array}{l}\text { Усічення та поєднання частин } \\
\text { декількох слів }\end{array}$ & $\begin{array}{l}\text { FörMig (Förderung von Kindern und } \\
\text { Jugendlichen mit Migrationshintergrund) }\end{array}$ & 1 & \\
\hline & $\begin{array}{c}\text { Усічення та поєднання першої } \\
\text { й останньої літер слова }\end{array}$ & Dr. (Doktor) & 1 & \\
\hline & $\begin{array}{c}\text { Усічення та поєднання складів } \\
\text { слова }\end{array}$ & Azubi (Auszubildende) & 1 & \\
\hline & $\begin{array}{c}\text { Усічення та поєднання літер, } \\
\text { складів та частин слова } \\
\end{array}$ & $\begin{array}{c}\text { SprasiBEQ (Sprachsensibilierung in den } \\
\text { beruflichen Qualifizierung) }\end{array}$ & 1 & \\
\hline & Усічення слова із цифрами & Sek-II (Sekundarschule II) & 1 & \\
\hline & $\begin{array}{c}\text { Усічення слова з літерами та } \\
\text { цифрами }\end{array}$ & G9-Abi (neunjähriges Gymnasium) & 1 & \\
\hline & $\begin{array}{l}\text { Телескопізми (поєднання почат- } \\
\text { кової та кінцевої частин слів) }\end{array}$ & $\begin{array}{l}\text { MINTegration (minderheitliche } \\
\text { Integration) }\end{array}$ & 1 & \\
\hline & \multicolumn{2}{|c|}{ УСБОГО } & 123 & 4,1 \\
\hline
\end{tabular}

\section{ЛIТЕРАТУРА}

1. Бирюкова Е. Функционирование аббревиатур в современной речи : дис. ... канд. филол. наук. Москва, 2007. 309 с.

2. Дужа-Задорожна М. Особливості абревіатур у німецькій економічній мові. Львів : Видавництво національного університету «Львівська політехніка», 2007. С. 94-97.

3. Дюжикова Е. Аббревиация сравнительно со словосложением : дис. ... докт. филол. наук. Москва, 1997. $340 \mathrm{c}$.

4. Петренко О. Особливості абревіацій та скорочень у німецькій термінології робототехніки. Вчені записки Таврійського національного університету імені В.І. Вернадського. Серія «Філологія. Соціальні комунікації». 2020. Т. 31 (70). № 1. Ч. 2. С. 166-169.

5. Книшенко Н. Абревіація в системі сучасної дорожньо-будівельної термінологічної номінації. Вісник Начіонального університету «Львівська політехніка». 2010. № 675 : Проблеми української термінологіï. С. 19-22.

6. Лейчик В. Пиар и другие аббревиатуры. Русская речь. 2002. № 5. С. 40-44.

7. Халіновська Л. Особливості абревіації в українській авіаційній термінології. Вісник Національного університету «Львівська політехніка». 2010. № 675 : Проблеми української термінології. С. 50-53.

8. Armbruster Klaus. DER GESAMTPERSONALRAT DER LEHRERINNEN UND LEHRER beim Staatlichen Schulamt für den Landkreis Darmstadt-Dieburg und die Stadt Darmstadt. Darmstadt, den 24.3.2020. URL: https://www.gew-darmstadt.de/fileadmin/user_upload/GPRLL-DADI_Erlaeuterungen_ zur_mail_letzter_Woche_.pdf. 
9. Budde Monika Angela. Mehrsprachigkeit - Language Awareness - Sprachbewusstheit. Einführung. Zeitschrift für interkulturellen Fremdsprachenunterricht. 2016. № 21 : 2. S. 1-4.

10. Demmig Silvia. Language awareness und Deutsch als Fremdsprache. Zeitschrift für interkulturellen Fremdsprachenunterricht. 2016. № $21: 2$. S. 68-75.

11. Dinger Otto. Fremdsprachen Lehren: Vorlesungen zur Didaktik des Fremdsprachenunterrichtes Deutsch als Zweitsprache. Ushhorod Lira, 2004. 98 S.

12. Duden 9 - Duden. Deutsches Universalwörterbuch. 9, vollständig überarbeitete und erweiterte Auflage 2019. Buch. 2144 S.

13. Felger Susanne. Azubis informieren SchülerInnen. Eine Kooperation von Unternehmen, Schulen, Jugendberufshilfe und Stadt Weinheim. Freudenberg Stiftung, 2013. 28 S.

14. Funk Hermann. Berufsbezogener Fremdsprachenunterricht. Handbuch Fremdsprachenunterricht / KarlRichard Bausch, Herbert Christ, Hans-Jürgen Krumm (Hg.). Tübingen, 2003. S. 175-179.

15. Gogolin Inge Durchgängige Sprachbildung Qualitätsmerkmale für den Unterricht. Zusammenarbeit mit der FÖRMIG-AG Durchgängige Sprachbildung. Waxmann Verlag GmbH, 2011.28 S.

16. Hollmann Victoria. MINTegration. Lehrkraft für besondere Aufgaben. Mercator Institut für Sprachförderung und Deutsch als Zweitsprache. 2017. URL: https://www.mercator-institut-sprachfoerderung.de/de/ studium-weiterbildung/ausgewaehlte-lehrprojekte/mintegration.

17. Lehrer NRW. Verband für den Sekundarbereich. Pädagogik \& HOCHSCHUL VERLAG / Brigitte Balbach et al. Düsseldorf, 2014. 1.28 S.

18. Lehrer NRW. Verband für den Sekundarbereich. Pädagogik \& HOCHSCHUL VERLAG / Brigitte Balbach et al. Düsseldorf, 2014. 2.28 S.

19. Lehrer NRW. Verband für den Sekundarbereich. Pädagogik \& HOCHSCHUL VERLAG / Brigitte Balbach et al. Düsseldorf, 2019. $230 \mathrm{~S}$.

20. Lehrer NRW. Verband für den Sekundarbereich. Pädagogik \& HOCHSCHUL VERLAG / Brigitte Balbach et al. Düsseldorf, 2020. 2. 30 S.

21. Morfeld Petra. Sprachenzertifikate. Handbuch Fremdsprachenunterricht / Karl-Richard Bausch, Herbert Christ, Hans-Jürgen Krumm (Hg.). Tübingen. 2003, S. 384-387.

22. Nerlich Barbara. Vergleichende Studie der L1-Lesekompetenz bilingual unterrichteter Schüler der Klassenstufen 7 und 10 an schleswigholsteinischen Gymnasien : Dissertation zur Erlangung des Doktorgrades der Philosophischen Fakultät der Christian-Albrechts-Universität zu Kiel, 2013. 225 S.

23. Nissen Rudolf. Formen der Leistungsmessung in der unterrichtlichen Praxis. Handbuch Fremdsprachenunterricht / Karl-Richard Bausch, Herbert Christ, Hans-Jürgen Krumm (Hg.). Tübingen, 2003. S. 370-373.

24. PONS Großwörterbuch Deutsch als Fremdsprache : 110.000 Stichwörter, Wendungen und Beispielsätze. Stuttgart : Klett, 2018. 1707 S.

25. Reiske Heinz. Fremdsprachenunterricht in der Erwachsenbildung in deutschsprächigen Ländern. Handbuch Fremdsprachenunterricht / Karl-Richard Bausch, Herbert Christ, Hans-Jürgen Krumm (Hg.). Tübingen, 2003. S. 86-92.

26. Wahrig-Burfeind Renate. WAHRIG Deutsches Wörterbuch. 9. Auflage. Brockhaus, 2011. 1730 S.

\section{REFERENCES}

1. Biriukova E.V. (2007) Funktsionirovanie abbreviatur v sovremennoi rechi [Funktion of Abbreviation in Modern Communication]. MPGU. 309 p.

2. Duzha-Zadorozhnia M.P. (2007). Osoblyvosti abreviatur u nimetskii ekonomichnii movi [Features of Abbreviations in the German Language of Economics]. Vydavnytsnvo natsionalnogo universytetu "Lvivska politechnika" [National University Publishing House "Lviv Polytechnics"]. P. 94-97.

3. Diuzhikova E.A. (1997). Abbreviatsiia sravnitelno so slovozheniem [Abbreviation compared to Compounding]. Moskva. $340 \mathrm{p}$.

4. Petrenko O.V. (2020). Osoblyvosti abreviatsii ta skorochen u nimetskii terminologii robototechniky [Features of Abbreviation and Shortenings in the German Technology of Robotics]. Vcheni zapysky TNU imeni V.I. Vernandskogo [Bulletin of Vernadsky TNU]. Filologiia. Sotsialni komunikatsii. P. 166-169.

5. Knyshenko N.P. (2010). Abreviatsiia v systemi suchasnoi dorozhno-budivelnoi terminologichnoi nominatsii [Abbreviation in the System of Road Construction Terminological Nomination]. Visnyk natsionalnogo universytetu "Lvivska politechnika" [Bulletin of National University "Lviv Polytechnics"]. Problemy ukrainskoi terminologii. P. 19-22.

6. Leichik V.M. (2002). Piar i drugie abbreviatury [PR and other Abbreviations]. Russkaia rech. [Russian speech]. Vol. 5. P. 40-44. 
7. Halinovska L.A. (2010). Osoblyvosti abreviatsii v ukrainskii aviatsiinii terminologii [Features of Abbreviation in the Ukrainian Aviation Terminology]. Visnyk natsionalnogo universytetu "Lvivska politechnika" [Bulletin of National University "Lviv Polytechnics"]. Problemy ukrainskoi terminologii. P. 50-53.

8. Armbruster, Klaus. DER GESAMTPERSONALRAT DER LEHRERINNEN UND LEHRER beim Staatlichen Schulamt für den Landkreis Darmstadt-Dieburg und die Stadt Darmstadt. Darmstadt, den 24.3.2020. https://www.gew-darmstadt.de/fileadmin/user_upload/GPRLL-DADI_Erlaeuterungen_zur_ mail_letzter_Woche_.pdf.

9. Bud̄̄e, Monika Angela (2016). Mehrsprachigkeit - Language Awareness - Sprachbewusstheit. Einführung. Zeitschrift für interkulturellen Fremdsprachenunterricht 21: 2, S. 1-4.

10. Demmig, Silvia (2016), Language awareness und Deutsch als Fremdsprache. Zeitschrift für interkulturellen Fremdsprachenunterricht $21: 2$, S. 68-75.

11. Dinger, Otto. Fremdsprachen Lehren: Vorlesungen zur Didaktik des Fremdsprachenunterrichtes Deutsch als Zweitsprache. Ushhorod Lira, 2004. 98 S.

12. Duden 9 - Duden. Deutsches Universalwörterbuch. 9., vollständig überarbeitete und erweiterte Auflage 2019. Buch. 2144 S.

13. Felger, Susanne (2013), Azubis informieren SchülerInnen. Eine Kooperation von Unternehmen, Schulen, Jugendberufshilfe und Stadt Weinheim. Freudenberg Stiftung, $28 \mathrm{~S}$.

14. Funk, Hermann. Berufsbezogener Fremdsprachenunterricht. In: Karl-Richard Bausch / Herbert Christ / Hans-Jürgen Krumm (Hg.): Handbuch Fremdsprachenunterricht. Tübingen. 2003, S. 175-179.

15. Gogolin, Inge (2011), Durchgängige Sprachbildung Qualitätsmerkmale für den Unterricht. In Zusammenarbeit mit der FÖRMIG-AG Durchgängige Sprachbildung. Waxmann Verlag GmbH, 28 S.

16. Hollmann, Victoria (2017), MINTegration. Lehrkraft für besondere Aufgaben. Mercator Institut für Sprachförderung und Deutsch als Zweitsprache. https://www.mercator-institut-sprachfoerderung.de/de/ studium-weiterbildung/ ausgewaehlte-lehrprojekte/mintegration.

17. Lehrer NRW. Verband für den Sekundarbereich. In: Balbach, Brigitte; Heribert Brabeck, Ulrich; Brambach, Frank Görgens; Michael König, Jochen. Pädagogik \&HOCHSCHUL VERLAG, Düsseldorf, 1 (2014), 28 S.

18. Lehrer NRW. Verband für den Sekundarbereich. In: Balbach, Brigitte; Heribert Brabeck, Ulrich; Brambach, Frank Görgens; Michael König, Jochen. Pädagogik \&HOCHSCHUL VERLAG, Düsseldorf, 2 (2014), 28 S.

19. Lehrer NRW. Verband für den Sekundarbereich. In: Balbach, Brigitte; Heribert Brabeck, Ulrich; Brambach, Frank Görgens; Michael König, Jochen. Pädagogik \&HOCHSCHUL VERLAG, Düsseldorf, 2 (2019), 30 S.

20. Lehrer NRW. Verband für den Sekundarbereich. In: Balbach, Brigitte; Heribert Brabeck, Ulrich; Brambach, Frank Görgens; Michael König, Jochen. Pädagogik \&HOCHSCHUL VERLAG, Düsseldorf, 2 (2020), 30 S.

21. Morfeld, Petra. Sprachenzertifikate. In: Karl-Richard Bausch/ Herbert Christ/ Hans-Jürgen Krumm (Hg.): Handbuch Fremdsprachenunterricht. Tübingen. 2003, S. 384-387.

22. Nerlich, Barbara. Vergleichende Studie der L1-Lesekompetenz bilingual unterrichteter Schüler der Klassenstufen 7 und 10 an schleswigholsteinischen Gymnasien. Dissertation zur Erlangung des Doktorgrades der Philosophischen Fakultät der Christian-Albrechts-Universität zu Kiel, 2013. 225 S.

23. Nissen, Rudolf. Formen der Leistungsmessung in der unterrichtlichen Praxis. In: Karl-Richard Bausch / Herbert Christ/ Hans-Jürgen Krumm (Hg.): Handbuch Fremdsprachenunterricht. Tübingen. 2003, S. 370-373.

24. PONS Großwörterbuch Deutsch als Fremdsprache: 110.000 Stichwörter, Wendungen und Beispielsätze. Stuttgart: Klett, 2018.1707 S.

25. Reiske, Heinz. Fremdsprachenunterricht in der Erwachsenbildung in deutschsprächigen Ländern. In: Karl-Richard Bausch / Herbert Christ / Hans-Jürgen Krumm (Hg.): Handbuch Fremdsprachenunterricht. Tübingen. 2003, S. 86-92.

26. Wahrig-Burfeind, Renate. WAHRIG Deutsches Wörterbuch. 9. Auflage. Brockhaus, 2011. 1730 S. 